Çukurova Üniversitesi Mühendislik Fakültesi Dergisi, 36(3), ss. 769-780, Eylül 2021

Çukurova University Journal of the Faculty of Engineering, 36(3), pp. 769-780, September 2021

\title{
Agro-Endüstriyel Atık Olan Elma Posalarının Box-Behnken Yanıt Yüzey Metodolojisi ile Alkali Ön İşlem Optimizasyonu
}

\author{
Özgecan MADENLI' ${ }^{* 1}$, Ece Ümmü DEVECí ${ }^{1}$ \\ ${ }^{1}$ Niğde Ömer Halisdemir Üniversitesi, Mühendislik Fakültesi, Çevre Mühendisliği Bölümü, \\ Niğde
}

Geliş tarihi: 02.06.2021

Kabul tarihi: 13.09 .2021

$\ddot{\mathbf{O} z}$

Agro-endüstriyel atıklar lignoselülozik yapıya sahip biyokütlelerdir. Biyokütleler ön işlem yöntemleri ile fermente şeker olarak geri kazanılması biyoyakıt üretiminde büyük önem arz etmektedir. Bu çalışmada basınçlı ve basınçsız ortamlarda alkali potasyum hidroksit $(\mathrm{KOH})$ ile elma posası atıklarının ön işlemi yöntemiyle toplam şeker ve indirgenmiş şeker potansiyeli yanıt yüzey metodolojisi olan Box Behnken istatiksel modeli ile incelenmiştir. Optimum çalışma koşulları zaman (30-90 dk), KOH dozu (\%1-3) ve katı oranı $(\% 2,5-7,5)$ olarak incelenmiştir. Alkali potasyum hidroksit ön işleminde basınçlı ortamda reaksiyon süresi 60 dakikada ve $\% 5$ katı oranında toplam şeker miktarının 22,36 g/L'ye ulaştığ1 belirlenmiştir.

Anahtar Kelimeler: Alkali ön işlem, Elma posası, Yanıt yüzey metodolojisi, Biyoyakıt potansiyeli

\section{Alkaline Pre-Treatment Optimization of Agro-Industrial Waste Apple Pulp with Box-Behnken Response Surface Methodology}

\begin{abstract}
Agro-industrial wastes are biomass with lignocellulosic structure. The recovery of biomass as fermented sugar by pre-treatment methods is of great importance in biofuel production. Pre-treatment methods such as physical, chemical, physico-chemical, biological and combined are applied to agro-industrial wastes. In this study, the total sugar and reduced sugar potential in pressurized and non-pressurized environments by pretreatment of alkali potassium hydroxide $(\mathrm{KOH})$ and apple pulp wastes were investigated with the Box Behnken statistical model, which is the response surface methodology. Optimum working conditions were examined as time (30-90 $\mathrm{min}), \mathrm{KOH}$ dose (1-3\%) and solids ratio (2.5-7.5\%). In alkali potassium hydroxide pre-treatment, the reaction time in pressurized medium was 60 minutes and the total sugar amount at $5 \%$ solid rate reached $22,36 \mathrm{~g} / \mathrm{L}$.
\end{abstract}

Keywords: Alkali pretreatment, Apple pulp, Response surface methodology, Biofuel potential

*Sorumlu yazar (Corresponding author): Özgecan MADENLİ, ozgemadenli@gmail.com 


\section{GİRIŞ}

Şuan gelişmiş ve gelişmekte olan ülkelerde dahil tüm dünya petrol, kömür ve doğalgaz gibi fosil yakıtlardan enerji üretmektedir [1]. Kullanılan yakıt kaynaklarının sürdürülemez olmasının yanında tüketimi esnasında atmosfere sera gazı emisyonu salınımına yol açmaktadır. Sanayi devriminden bu zamana kadar fosil yakitlardan kaynaklı $\mathrm{CO}_{2}$ emisyonu yaklaşı 416,08 ppm düzeylerindedir. $\mathrm{Bu}$ durum dünyanın sıcaklığını arttırmaktadır. Kontrolü sağlanmadığı sürece bu yüzyılda $\mathrm{CO}_{2}$ emisyon miktarı 550 ppm'i geçeceği ön görülmektedir [2].

İklim değiş̧ikliğine uyum sağlayacak, $\mathrm{CO}_{2}$ emisyonlarını azaltacak ve artan enerji talebi ihtiyacını karşılayacak yenilenebilir enerji türü olan biyoyakıtlardır [3]. Biyokütle temelli yakıtlar yenilenebilir kaynaklardan elde edildiğinden dolayı sürdürülebilir yakıtlar olarak adlandırılmaktadır [4].

Biyoyakıt üretimi, üretim esnasında kullanılacak biyokütle türüne bağlı olarak 3 nesile ayrılmaktadır [5]. Birinci nesil biyoyakitlar genel olarak yapılarında şeker, nişasta ve yağ depolayan bitki türlerinden elde edilmektedir. Bu tür biyokütleler ile biyoyakıt üretmek ucuz ve kolay olmaktadır [6]. Fakat güvenli ve temiz gıdaya ulaşmanın zorluğu göz önünde bulundurulduğunda tarım alanlarının enerji bitkisi yetiştiriciliğinde kullanılması istenmemektedir [7]. Gıda üretiminde yaşanacak sorunların yarattığ endişeden dolayı tarımsal gıda endüstrilerinin yan ürünlerinden biyoyakıt üretimine olan talep her geçen gün artmaktadır [8]. Bu şekilde ucuz hammadde kaynağı ile doğa dostu, ekonomik biyoyakıt üretmek mümkündür.

Tarımsal sanayi atıklar, geniş bir ürün çeşidine sahiptir. Bunlardan en önemlileri mahsul, hayvan atıkları ve tarımsal endüstri atıklardır [9]. Tarımsal endüstriyel atıklar odunsu selülozik bir yapıya sahip biyokütle olmasından dolayı enerji, yakıt ve kimyasal üretim için hammadde olarak kullanılması büyük önem arz etmektedir [10]. Biyokütlenin ön işleme tabi tutulması, enzimatik hidroliz sırasında fermente olabilen şekerlerin verimli şekilde üretimini sağlamaktadır [11]. Ön işlem sırasında kullanılacak yöntemler ekonomik olmasının yanı sıra reaksiyonları engelleyecek herhangi toksik bileşiklerin oluşumunu engellemelidir. [12]. Asit, alkali, hidrojen peroksit, enzimatik, ultrason, termal uygulama ve basınç teknikleri gibi biyokütlenin yakıt üretim kapasitesini arttırmak için bazı etkili ön işlem teknikleridir. Ayrıca biyokütlenin hammadde olarak ön işlemden geçirilmesi mikroorganizmaların biyokütleyi daha kolay kullanabilmesine ve işlenmemiş biyokütleye göre çok daha fazla miktarda dönüşüm gerçekleştirdiğinden dolayı biyoyakıt üretim maliyetini düşürebilmektedir $[13,14]$. Tüm bu bilgiler göz önünde bulundurularak ön işlem yöntemlerinden hangisinin en uygun olduğuna maliyet, uygulama kolaylığı ve çevreye duyarlılığ açısından test edilerek karar verilmektedir [10].

Alkali ön işlemler biyokütlenin, lignin ve ksilanı bağlayan ester bağlarını bozarak lignoselülozik yapıyı etki hale getirerek hem selüloz hem de hemiselüloz bakımından zenginleştirmektedir [15]. Alkali ön işlem uygulamaları diğer ön işlem proseslerine göre düşük sıcaklık, basınç ve daha kısa alıkonma süresi kullanılmaktadır. Sodyum hidroksit, amonyak, peroksit, potasyum hidroksit ve kireç gibi alkali kimyasallar ön işlem proseslerinde tercih edilmektedir. $\mathrm{Bu}$ alkali ön işlemler daha uygun maliyetli ve daha düşük enzim oranları ile selülozu glikoza dönüştürmektedir [16].

Lignoselülozik yapıya sahip biyokütleler seyreltik alkali ön ișleminden geçirilerek hidrolizatların verimliliğini değerlendirmişlerdir [16,17]. Çoğunlukla alkali ön işlem çalışmalarında şeker verimleri ve monosakkarid yapıların değişimleri incelenerek detaylandırılmıştır. Biyokütlenin hidrolize edilmesi ve yüksek yakıt potansiyeline ulaşılması için en uygun parametreler belirlenmesi önem arz etmektedir. 
$\mathrm{Bu}$ çalışmada tarımsal endüstriyel atık olan elma posası atıklarının biyoyakıt dönüşüm potansiyelini arttırmak amaciyla potasyum hidroksit $(\mathrm{KOH})$ ile basınçlı ve basınçsız ortamda ön işlem uygulamaları değerlendirmiştir. Ön işlem sürecinin bağımsız faktörlerini optimize etmek için BoxBehnken'in istatistiksel deneysel yöntemi kullanılmıştır.

\section{2. ÖNCEKİ ÇALIŞMALAR}

Lignoselülozik biyo kütle, bol, çevreye zararsız ve sürdürülebilir olduğu için günümüzün enerji ve çevresel endişelerini gidermek için çok uygundur. Lignoselülozik ön işlemde kaydedilen ilerlemeler incelendiğinde alkali ön işlemin lignoselülozik biyo kütle bozunması toksik olmayan ve düşük maliyetli işlemler olarak ortaya çıkmıştır. Farklı alkali kimyasallarla yaptıkları ön işlem karşılaştırmasında KOH'a göre $\mathrm{NaOH}$ ön işleminin en yüksek alkali konsantrasyonunda sıcaklığında ve en düşük reaksiyon süresinde enerji kazanım oranının daha yüksek olduğunu bildirmişlerdir [18]. Alkali ön işlem olarak $\mathrm{KOH}$ tercih edilmesinin nedenlerinden biri de yapilan alkali ön işlem çalışmalarında biyo kütlenin biyodönüşümünün sıfir emisyonunu gerçekleştirmek için daha çevre dostu bir alkali olarak tercih edilmesi gerektiği rapor edildiğindendir [19]. Fermente şeker üretiminin daha temiz ve sürdürülebilir bir üretimi için $\mathrm{KOH}$ alkali ön işleminin daha önemli olduğunu vurgulayan başka bir çalışmada mısır koçanının \%13 KOH dozunda \%5'lik katı oranında 72 saat boyunca fermentasyon işleminin sonucunda \%90 oranında toplam şeker üretimini gerçekleştirdiklerini bildirmişleridir. Ayrıca bazı biyo kütlelerin (bambu, kauçuk ve çim) biyo yakıt üretiminde kullanımı ve şeker dönüşüm potansiyelleri düşüktür. $\mathrm{Bu}$ biyokütlelerden biri olan çimlerin $\mathrm{KOH}$ ön işlemi ile $100 \mathrm{gr}$ hammaddenin $121^{\circ} \mathrm{C}$ 'de 1 saat fermentasyon süresinde $19 \mathrm{~g}$ şeker üretiminin olduğunu ve enerji potansiyelini arttırmaktadır [19]. Çoğu ön işlem geleneksel ısıtma yöntemi ile yapılmaktadır. Çim biyokütlesinin mikrodalga destekli alkali ön işleminde 100 gr hammadde de 34,5 gr toplam şeker kazanımı olduğu belirtilmiştir [20]. Buğday samanı biyokütlesinin $\mathrm{KOH}$ ön işleminde kombinasyon çalışması yaparak sadece $\mathrm{KOH}$ ön işlemine kıyasla $\% 80$ şeker üretimini arttırmışlardır [21]. Yapılan araştırmalarda potasyum hidroksit gibi alkali tuzların seçimi sürdürülebilirliği değerlendirildiğinde fermentasyon sonrası fermente sivilarının bitkilerde gübre olarak kullanımı etkin bir geri kazanım ve temiz üretim sağlamaktadır.

\section{MATERYAL VE METOT}

\subsection{Materyal ve Metot}

Meyve suyu fabrikalarından tarımsal endüstriyel olarak çıkan elma posaları Niğde'de yerel bir meyve suyu fabrikasından temin edilmiştir. İlk adımda elma posaları $50{ }^{\circ} \mathrm{C}$ 'de 48 saat kurutulmuştur ve ardından IKA MF10 öğütücü ile 1,0, 0,6 ve 0,2 ağ elek içinden geçmek üzere ögütülmüştür. Parçacık boyutunu tanımlarken alt ve üst elek açıklıkları kullanılmıştır. Tüm deneyler 250 ml'lik roch şişelerinde gerçekleştirildi. Tüm numuneler, analiz için $0,25 \mu \mathrm{m}$ membran filtre ile süzüldü ve 10 dakika süreyle $10,000 \mathrm{rpm}$ 'de santrifüjlenmiştir. Elde edilen süpernatantlarda toplam şeker ve indirgeme şeker analizleri yapılmıştır.

\section{2. Ön İşlem Yöntemi}

İki farklı koşul altında alkali ön işlem uygulandı. Ön işlem sıcağa dayanıklı borosilikat roch şişelerinde $1 \mathrm{~atm}$ basınç altında $100^{\circ} \mathrm{C}$ (basınçsız) ve 1sıya dayanıklı borosilikat roch şişelerinde otoklavda 1,2 atm basınç altında $121^{\circ} \mathrm{C}$ 'de (basınçl1) potasyum hidroksit alkali asit ile gerçekleştirilmiştir. Optimum reaksiyon koşullarını elde etmek için kimyasal miktarı, katı miktarı ve zaman parametreleri Box-Behnken yanıt yüzey metodolojisine göre optimize edilmiştir. 


\section{3. İstatiksel Yöntem}

Deneyler sırasında minimum kimyasal kullanımı ve etkili zaman yönetimi için çoklu faktörlerin optimizasyonu için istatiksel yöntem olan yanıt yüzey metodolojisi (RSM) kullanılmışıtr. RSM ile optimum bir sonuç elde edebilmek için deney desenleri kullanılmaktadır. RSM istatiksel yönteminde farklı deneysel tasarımlar bulunmaktadır. RSM istatiksel yöntemlerden biri olan Box-Behnken istatiksel deney tasarım 3 bağımsız faktörün tepki fonksiyonları üzerindeki etkileri belirlemek için toplam şeker oranını arttırmak ve $\mathrm{KOH}$ kullanımını ve enerji tüketimini minimize etmek için en uygun şartları belirlemek için kullanılmıştır. Box-Behnken deneysel tasarımları faktör kombinasyonlarının değişken uzay kenarlarının orta noktalarında ve merkezde olduğu gömülü faktöriyel veya kesirli faktöriyel noktaları olmayan bağımsız ikinci dereceden bir tasarımdır. Tarımsal endüstriyel atıkların ön işlem çalışmalarında seçilen faktörler, atığın selülozik yapısının bozulma oranını belirlemek ve ayrıca ön işlem deneyleri sırasında aşırı kimyasal kullanımını önlemek için çok önemlidir. BoxBehnken deneysel tasarımı, birinci ve ikinci derece katsayıların verimli bir şekilde tahmin edilmesini sağlamaktadır. Elma posası atığına çeşitli faktörler ile ön işlem uygulanmıştır.

Box-Behnken deney tasarımı, tüm farklı ön işlemler için optimum koşulları bulmak için kullanılmıştır. Box-Behnken deneysel tasarımı için istatistiksel bir model oluşturmak için Design Expert 7.0.0 deneme sürümü yazılımı kullanılmıştır. Bu deneysel tasarım için üç farklı faktör ve 3 seviye kullanılmıştır.

\subsection{Analiz}

Elma posas1 süpernatantlar1, 3,5-dinitrosalisilik asit reaktifi kullanılarak DNS yöntemine dayalı olarak toplam indirgeme şekerinin konsantrasyonunu belirlemek için kullanıldı. $3 \mathrm{ml}$ hazırlanan numune, $3 \mathrm{ml}$ DNS ile karıştıııldı ve vorteks ile homojen hale getirilmiştir. Daha sonra örnekler buz ile soğutulmuş ve ardından 575 nm'de spektrometrik ölçüm ile yapılmıştır [22]. Toplam şeker konsantrasyonu fenol-sülfürik asit yöntemi ile ölçülmüştür. $0,5 \mathrm{ml}$ numuneye $0,5 \mathrm{ml}$ $\% 5$ fenol solüsyonu ilave edilerek ardından vorteks ile homojenize edildi. 2,5 ml \%98'lik $\mathrm{H}_{2} \mathrm{SO}_{4}$ karışıma ilave edildi ve daha sonra tekrar karıştırılmıştır. Spektrofotometrik ölçüm 30 dakika sonra $488 \mathrm{~nm}$ dalga boyunda yapılmıştır [23].

\section{BULGULAR VE TARTIŞMA}

\subsection{Box-Behnken Modeli Yüzey Yanıtları}

Türkiye'de tarımsal üretim açısından zengin bölgelerden biri İç Anadolu Bölgesidir. Bu bölgede yer alan Niğde ilinde 1100 hektar tarım arazisinde yaklaşık 19.000 ton elma üretilmektedir. Bölgede hem sanayi hem de tarımsal üretim söz konusu olduğundan gelen tarımsal sanayi atıkları arasında elma önemli bir yer tutmaktadır.

Gıda endüstrisinde geniş bir yelpazeye sahip olan meyve suyu fabrikalarının üretim sonrasında ciddi miktarlarda atık oluşmaktadır. $\mathrm{Bu}$ atıkların bertarafinda zorluklar mevcuttur. Biyo kütle olarak bu meyve suyu fabrikası atıkları önemli biyo-enerji değerine sahiptir ve ucuz hammadde kaynağıdır. Agro-endüstriyel atıklardan yakıt üretimi temiz enerji üretimi, iklim değişikliğine katkısı ve atıkların kaynağında yönetimi bakımından üç noktada ele alınmalıdır. Bu bağlamda elma posası atıklarının biyo yakıt verimini arttırmak için potasyum hidroksit ile alkali ön işlem uygulanmıştır.

$\mathrm{KOH}$ alkali önişlemin optimizasyonu ile belirlenmesinde Box-Behnken istatistiksel modeli seçilmiştir. Basınçlı ve basınçsız ortamlar da $\mathrm{KOH}$ ön işlemi için; kimyasal oranı, zaman ve elma posası katı oranı faktörler belirlenerek düşük (-1), orta $(\mathrm{O})$ ve maksimum $(+1)$ seviyeler olarak belirtilmiştir. İstatistiksel değerler Çizelge 1'de verilmiştir. Bu yanıtlar Şekil 1, Şekil 2, Şekil 3 ve Şekil 4 de 3 boyutlu grafiklerle ayrıntılı olarak açıklanmıştır. 
Çizelge 1. Elma posaları KOH konsantrasyonu, zaman ve katı oranı için Box-Behnken deneysel dizayn ve yanitlar

\begin{tabular}{|c|c|c|c|c|c|c|c|}
\hline & & & & 1,2 Atm 10 & & $1 \mathrm{Atm} 121^{\circ} \mathrm{C}$ & \\
\hline $\begin{array}{l}\text { Deney } \\
\text { no }\end{array}$ & $\begin{array}{c}\mathrm{KOH} \\
\text { konsantrasyonu (\%) }\end{array}$ & $\begin{array}{c}\text { Zaman } \\
\text { (dk) }\end{array}$ & $\begin{array}{c}\text { Kat1 } \\
\text { oranı } \\
(\%) \\
\end{array}$ & $\begin{array}{c}\text { Toplam } \\
\text { şeker }(g / L)\end{array}$ & $\begin{array}{l}\text { İndirgenmiş } \\
\text { şeker }(\mathrm{g} / \mathrm{L})\end{array}$ & $\begin{array}{c}\text { Toplam şeker } \\
(\mathrm{g} / \mathrm{L})\end{array}$ & $\begin{array}{c}\text { İndirgenmiş } \\
\text { şeker }(\mathrm{g} / \mathrm{L})\end{array}$ \\
\hline 1 & 5,00 & 30 & 5,00 & 9,42 & 5,88 & 15,22 & 5,23 \\
\hline 2 & 3,00 & 60 & 5,00 & 9,68 & 5,31 & 18,70 & 8,73 \\
\hline 3 & 1,00 & 60 & 7,50 & 13,12 & 7,83 & 4,64 & 2,96 \\
\hline 4 & 1,00 & 30 & 5,00 & 5,21 & 3,21 & 12,94 & 4,83 \\
\hline 5 & 3,00 & 60 & 5,00 & 9,03 & 5,80 & 16,21 & 8,41 \\
\hline 6 & 3,00 & 90 & 7,50 & 11,43 & 6,42 & 14,62 & 5,68 \\
\hline 7 & 5,00 & 90 & 5,00 & 11,37 & 6,46 & 22,35 & 10,69 \\
\hline 8 & 3,00 & 30 & 2,50 & 8,53 & 5,71 & 7,88 & 5,82 \\
\hline 9 & 3,00 & 60 & 5,00 & 9,41 & 5,03 & 17,19 & 7,89 \\
\hline 10 & 3,00 & 60 & 5,00 & 9,07 & 5,34 & 16,93 & 7,34 \\
\hline 11 & 3,00 & 30 & 7,50 & 9,70 & 5,14 & 6,03 & 5,01 \\
\hline 12 & 3,00 & 90 & 2,50 & 14,17 & 6,58 & 4,12 & 2,33 \\
\hline 13 & 1,00 & 60 & 2,50 & 4,80 & 2,47 & 4,68 & 2,89 \\
\hline 14 & 5,00 & 60 & 2,50 & 10,28 & 6,20 & 4,96 & 2,88 \\
\hline 15 & 1,00 & 90 & 5,00 & 7,39 & 4,14 & 5,92 & 2,78 \\
\hline 16 & 5,00 & 60 & 7,50 & 16,57 & 8,92 & 16,27 & 8,98 \\
\hline
\end{tabular}

Elma posalarının biyoyakıt potansiyelini arttırmak için basınçlı ve basınçsız ortamda alkali ön işlem etkisi incelenerek toplam şeker ve indirgenmiş şeker konsantrasyonları belirlenmiştir. Bu değerler atığın biyoenerji potansiyelini ve bu potansiyelin ne kadar önişlem ile artacağını beklenmektedir. Basınçsız $100^{\circ} \mathrm{C}$ 'de yürütülen toplam şeker optimizasyon çalışmasına göre belirlenen Box Behnken modeline göre; 156,44 Model F değeri ve $\mathbf{R}^{\mathbf{2}}$ değerinin $\mathbf{0 , 9 9}$ olması modelin önemli olduğunu göstermektedir. Ayrıca 0,0500'den küçük "Prob $>F$ " değerleri de model terimlerinin anlamlı olduğunu gösterirken; $\mathrm{A}, \mathrm{B}, \mathrm{AB}, \mathrm{AC}, \mathrm{BC}$, $\mathrm{A}^{2}, \mathrm{C}^{2}, \mathrm{~A}^{2} \mathrm{C}$ önemli model terimleridir. Kodlanmış faktörler açısından son denklem ikinci dereceden olup (Eşitlik 1);

1/Toplam Şeker $=+0,11-0,032 * A-0,016 * B$

$+, 231 E-004 * C+9,530 E-003 * A * B+$

$0,024 * A * C+7,752 E-003 * B * C+0.019 * A^{2}$

$+3,346 E-003 * B^{2}-0,016 * C^{2}-3,106 E-$

$003 * A^{2 *} B-0,043 * A^{2} * C-1,484 E-003 * A^{*} B^{2}$

Basınçsız $100{ }^{\circ} \mathrm{C}$ 'de yürütülen toplam şeker optimizasyon çalışmasına göre belirlenen Box Behnken modeline göre; 55,06 $\mathrm{F}$ değeri ve $\mathbf{R}^{\mathbf{2}}$ değerinin 99,5 bulunması modelin doğruluğunu gösterir. Ayrıca 0,0500 'den küçük "Prob $>$ F" değerleri, model terimlerinin anlamlı olduğunu gösterir. Bu durumda $\mathrm{A}, \mathrm{AC}, \mathrm{A}^{2}, \mathrm{C}^{2}, \mathrm{~A}^{2} \mathrm{C}$ önemli model terimler ve modelin denklemi ikinci derecedendir (Eşitlik 2).

1/İndirgenmiş Şeker $=+0,19-0,064^{*} \mathrm{~A}-$

$0,015 * \mathrm{~B}+5,863 \mathrm{E}-03 * \mathrm{C}+0,013 * \mathrm{~A} * \mathrm{~B}$

$+0,057 * \mathrm{~A} * \mathrm{C}-3,936 \mathrm{E}-003 * \mathrm{~B} * \mathrm{C}+0,032 * \mathrm{~A}^{2}$

$+4,301 \mathrm{E}-004 * \mathrm{~B}^{2}-0,018 * \mathrm{C}^{2}-5,712 \mathrm{E}-003 * \mathrm{~A}^{2}$

$\mathrm{B}-0,087 * \mathrm{~A}^{2} \mathrm{C}+7,582 \mathrm{E}-003 * \mathrm{AB}^{2}$

Basınçlı $121{ }^{\circ} \mathrm{C}$ 'de 1,2 atm basınçta yürütülen optimizasyon çalışmasına göre belirlenen Box Behnken modeline göre; 42,89 Model F değeri ve $\mathbf{R}^{2}$ değerinin $\mathbf{0 , 9 9}$ olması, modelin önemli olduğunu gösterir. 0,0500'den küçük "Prob $>F$ " değerleri, model terimlerinin anlamlı olduğunu gösterir. $\mathrm{Bu}$ durumda $\mathrm{A}, \mathrm{C}, \mathrm{AB}, \mathrm{AC}, \mathrm{BC}, \mathrm{A}^{2}, \mathrm{C}^{2}$ önemli model terimleri olup model denklemi ikinci derecendir (Eşitlik 3).

Toplam Seker $=+17,26+2,98 * A+1,21 * B$

$+2,16 * C+3,54 * A * B+2,84 * A * C$

$+3,09 * B * C-1,84 * A 2-1,31 * B 2-7,78 * C 2-$

$1,18 * A 2 * B+0,65 * A 2 * C+1,70 * A * B 2$

Basınçlı $121{ }^{\circ} \mathrm{C}$ 'de 1,2 atm basınçta yürütülen optimizasyon çalışmasına göre belirlenen Box 
Agro-Endüstriyel Atık Olan Elma Posalarının Box-Behnken Yanıt Yüzey Metodolojisi ile Alkali Ön İslem Optimizasyonu

Behnken modeline göre; $23,13 \mathrm{~F}$ değeri ve $\mathbf{R}^{2}$ değerinin 99,5 modelin önemli olduğunu gösterir. 0,0500'den küçük "Prob>F" değerleri, model terimlerinin anlamlı olduğunu gösterir. $\mathrm{Bu}$ durumda $\mathrm{A}, \mathrm{AB}, \mathrm{AC}, \mathrm{BC}, \mathrm{A}^{2}, \mathrm{C}^{2}, \mathrm{~A}^{2} \mathrm{~B}$ önemli model terimleri olup, modelin denklemi ikinci derecendir (Eşitlik 4).

Indirgenmiş Şeker $=+8,10+1,50 * A-0,70 * B+$ $0,63 * C+1,88 * A * B+1,51 * A * C+1,04 * B * C-$ $1,25 * A^{2}-0,96 * B 2-2,42 * C 2+1,55 * A 2 * B$ $+0,91 * A 2 * C+0,58 * A * B$

\subsection{Basınçlı Ortamda KOH Ön İșlemi}

Organik maddeler üzerinde yapılan ön işlemler, biyokütle yüzey alanını ve gözenekliliği arttırarak, lignin yapılarını değiştirir ve aynı zamanda yarı selülozik bileşenleri parçalayarak selüloz kristalliğini azaltmaktadır. Bu etkiler enzimatik şekerlendirme aşamasını geliştirmektedir. Böylece fermentasyon süreçleri için geri kazanılabilen daha yüksek fermente edilebilir şekerler elde edilmektedir.

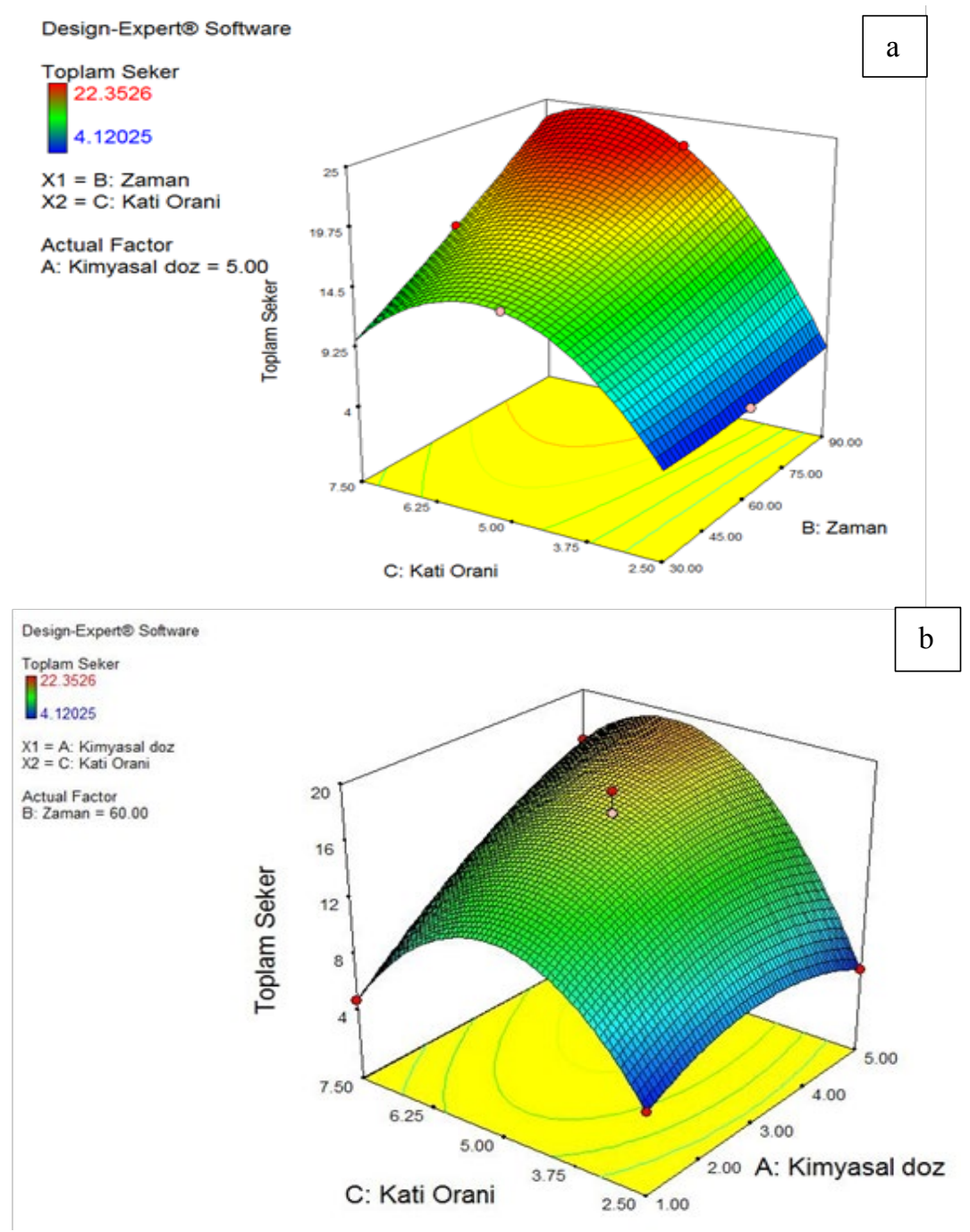




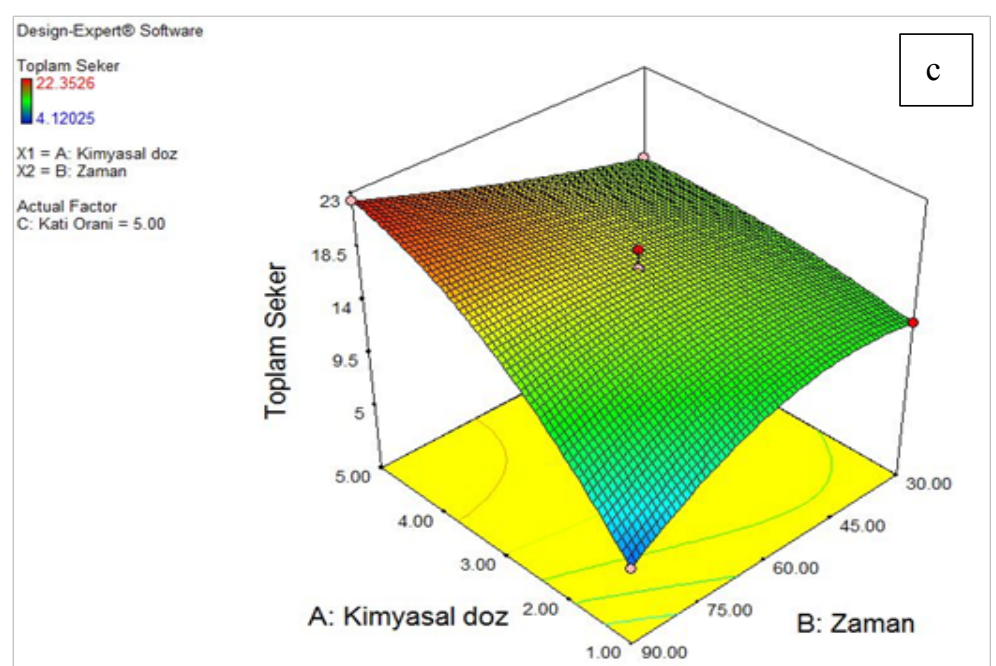

Şekil 1. KOH ön işlemi için farklı faktörlere bağlı toplam şeker konsantrasyonu

$121{ }^{\circ} \mathrm{C}$ 'de 1,2 atm basınçta gerçekleştirilen optimizasyon çalışmasında toplam şeker ve indirgen şeker değerindeki değişimler Şekil 1'de ayrıntılı olarak grafiklendirilmiştir. Katı oran faktörünün kimyasal doz faktörü ile birlikte seviye değişimleri aynı anda değerlendirildiğinde \%3'lük kimyasal dozun sabit olduğu önişlem koşulunda 1 saatlik reaksiyon süresinde $\% 5$ 'lik katı oranını uygulandığında $22,3 \mathrm{~g} / \mathrm{L}$ optimum toplam şeker değerine ulaşılmıştır (Şekil 1a). Katı oran faktörünün kimyasal doz faktörü ile birlikte seviye değişimleri aynı anda değerlendirildiğinde 60 dakikalık önişlemde optimum katı oranı $\% 5$ 'de kimyasal dozunun \%3 olduğu koşulda optimum toplam şeker değeri olan 22,3 g/L'ye ulaşılmaktadır (Şekil 1b). Katı oranı faktörünün seviyesi $\% 5$ olduğu koşul sabit tutulduğunda kimyasal doz faktörünün seviyesinin artması ile daha kısa zamanda optimum toplam şeker değerine ulaşılmaktadır. $\mathrm{Bu}$ durum kimyasal doz seviyesinin $\% 3$ optimal koşulda $22,3 \mathrm{~g} / \mathrm{L}$ toplam şeker değeri gibi yüksek sonuçlara ulaşması için optimal zaman olan 60 dakikada elde edilmesi zamanın süresinin dikkat çekici olduğunu ortaya koymaktadır (Şekil 1c).
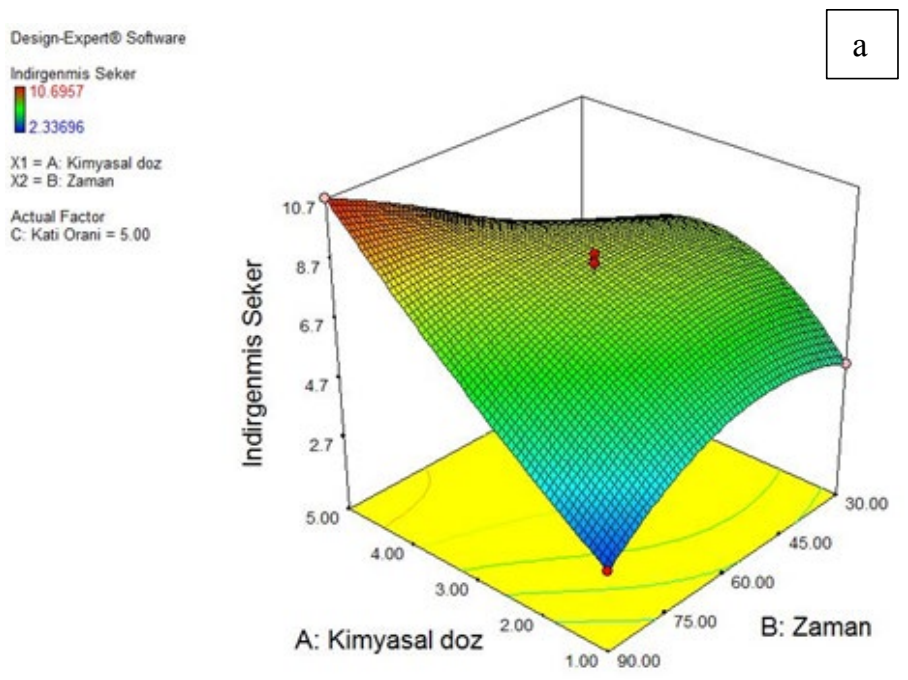
Agro-Endüstriyel Atık Olan Elma Posalarının Box-Behnken Yanıt Yüzey Metodolojisi ile Alkali Ön İslem Optimizasyonu
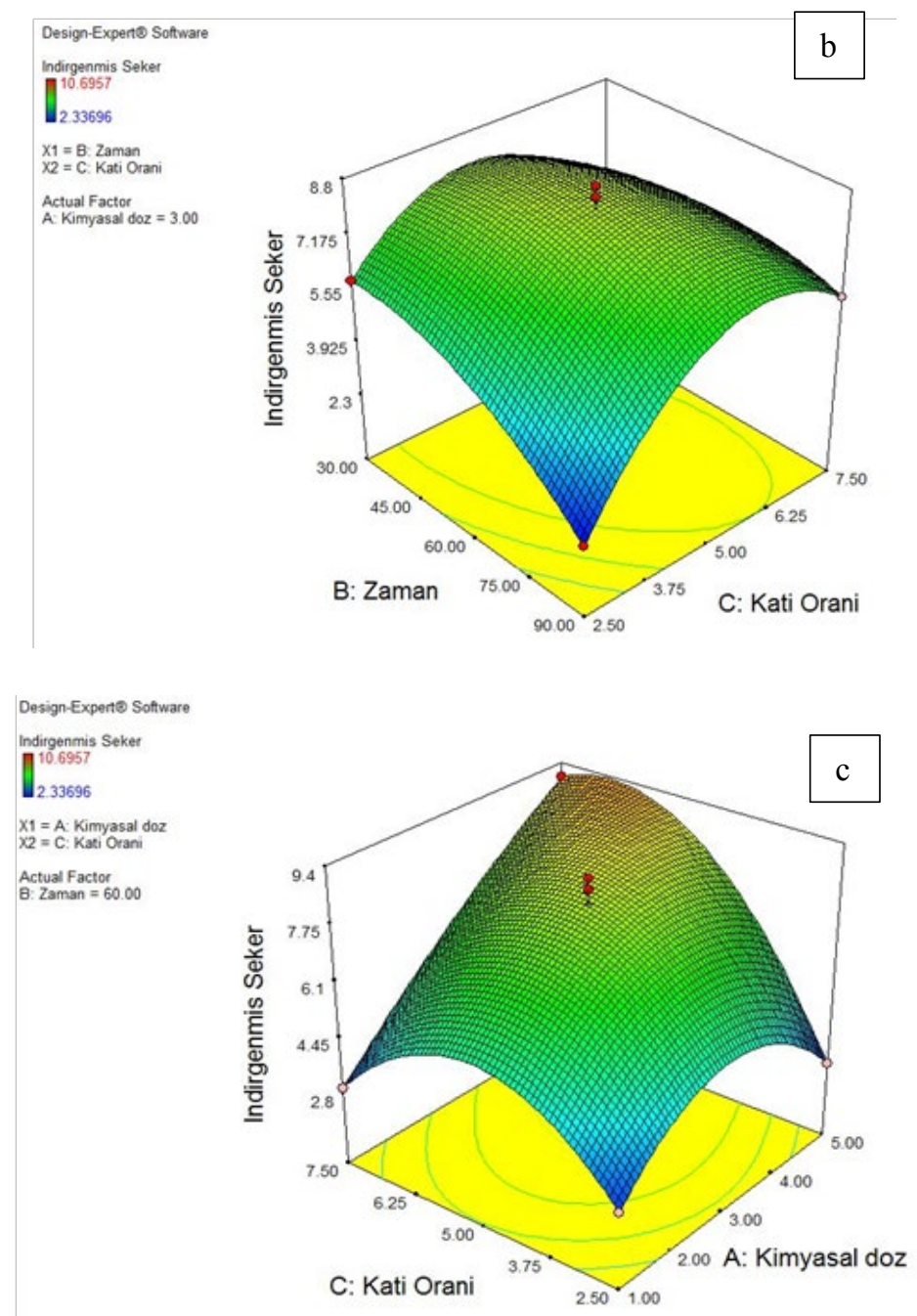

Şekil 2. Basınçlı KOH ön işlemi için farklı faktörlere bağlı indirgenmiş şeker konsantrasyonu

Basınçlı ortamda KOH ile yapılan önişlemde indirgenmiş şeker değerindeki değişim Şekil 2'de ayrıntılı olarak incelenmiştir. KOH konsantrasyonundaki değişim indirgen şeker değerini arttırırken zaman faktörünün seviyesinin optimum olduğu 60 dakikada maksimum değer olan 10,696 g/L indirgenmiş şeker değeri olarak belirlenmiştir. Zamana bağlı olarak katı oranındaki değişimin indirgenmiş şeker değerine olan etkisi Şekil 2b'de incelendiğinde katı oran faktör seviyesinin \%5 iken ve zaman faktör seviyesinin 60 dakika olduğu seviyede maksimum indirgenmiş şeker değerine ulaşmıştır. Ayrıca katı oran faktör seviyesinin kimyasal doz faktör seviyesi ile birlikte değerlendirildiğinde Şekil 2c'ye göre $\mathrm{KOH}$ optimum konsantrasyonu ve optimum kat1 derişiminde maksimum değere ulaşması ve $\mathrm{R}^{2}$ 'nin \%99 seviyesinde olması yapılan optimizasyon çalışmasının başarılı olduğunu göstermektedir.

\subsection{Basınçsız Ortamda KOH Ön İşlemi}

$100{ }^{\circ} \mathrm{C}$ 'de 1 atm basınçlı ortamda yapılan reaksiyonda indirgenmiş şeker ve toplam şeker 
üzerine etkisi incelenmiştir. Elde edilen veriler değerlendirildiğinde katı oranı faktör seviyesi azaldıkça reaksiyon süre faktörünün seviyesinin artması ile toplam şeker değeri maksimum değer olan 16,58 g/L değerine ulaşmıştır (Şekil 3a). Bu değer basınçlı ortam ile karşılaştırıldığında daha düşük kalmaktadır. Reaksiyon süresinin uzunluğu harcanacak olan enerjiden ve zamandan dolayı istenilmeyen bir durum olması nedeniyle bu koşulda daha kısa sürede daha yüksek verim elde edilen basınçlı koşullar daha çok tercih edilmesi gerekliliğini doğurmaktadır. Şekil 3b'de zaman faktörünün seviyeleri ile zaman faktörünün seviyeleri birlikte değerlendirildiğinde optimum zaman olan 60 dakikada \%3'lük $\mathrm{KOH}$ konsantrasyonunda optimum toplam şeker değeri olan 16,58'e ulaşırken kimyasal dozun artışına göre toplam şeker değerini maksimum değer olan 16,58 'e ulaşmıştır. Kimyasal doz faktörünün seviyesi ile katı oranı faktörünün seviyesi birlikte değerlendirildiğinde Şekil 3C'de görüldüğü gibi kimyasal dozun maksimum değer olan \%5'lik $\mathrm{KOH}$ konsantrasyonu ve $\% 7,5$ maksimum katı oranında maksimum toplam şeker değeri olan $16,58 \mathrm{~g} / \mathrm{L}$ 'ye ulaşılmıştır. Elde edilen verilerden de anlaşıldığı üzere basınçsız sistemler verimliliği ve uygulama açısından maliyetli olarak görülmektedir.
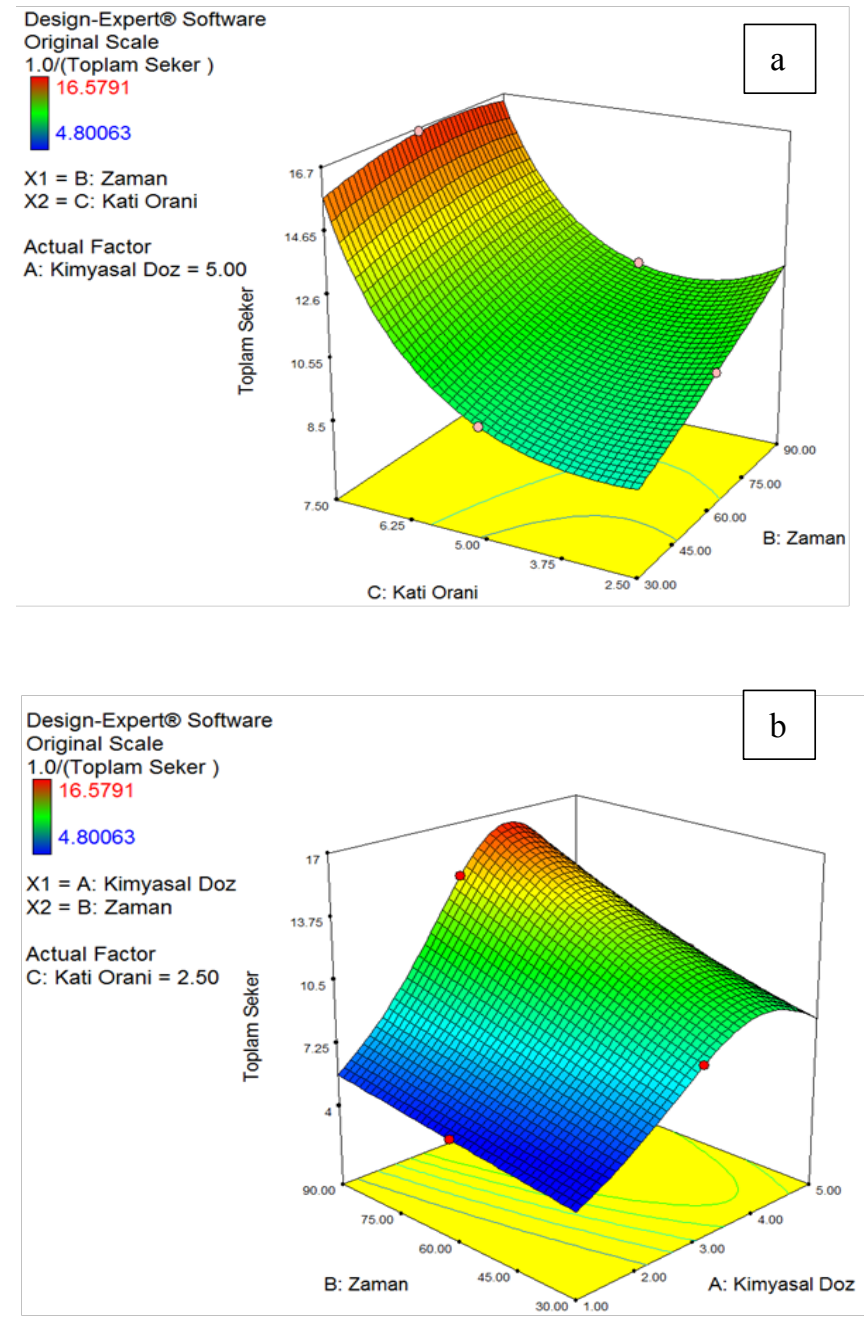
Agro-Endüstriyel Atık Olan Elma Posalarının Box-Behnken Yanıt Yüzey Metodolojisi ile Alkali Ön İslem Optimizasyonu

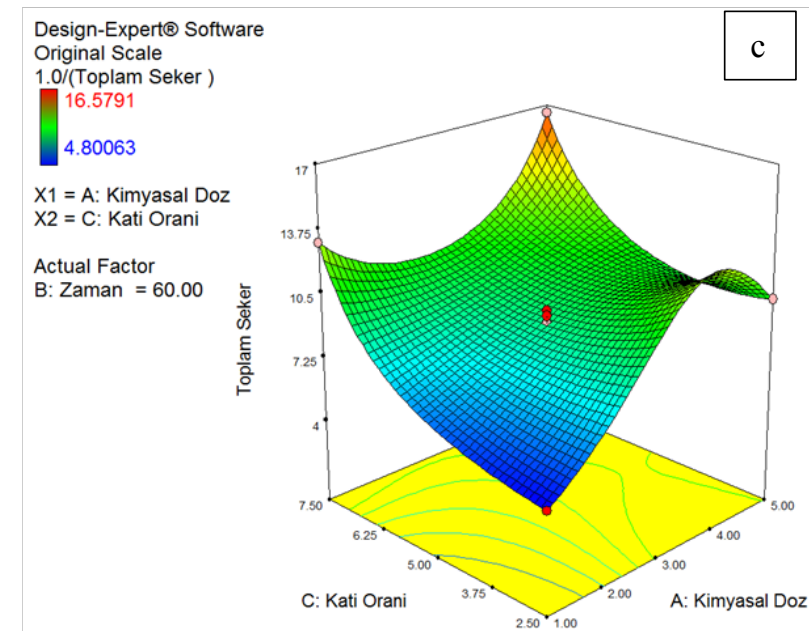

Şekil 3. Basınçsız KOH ön işlemi için farklı faktörlere bağlı toplam şeker konsantrasyonu
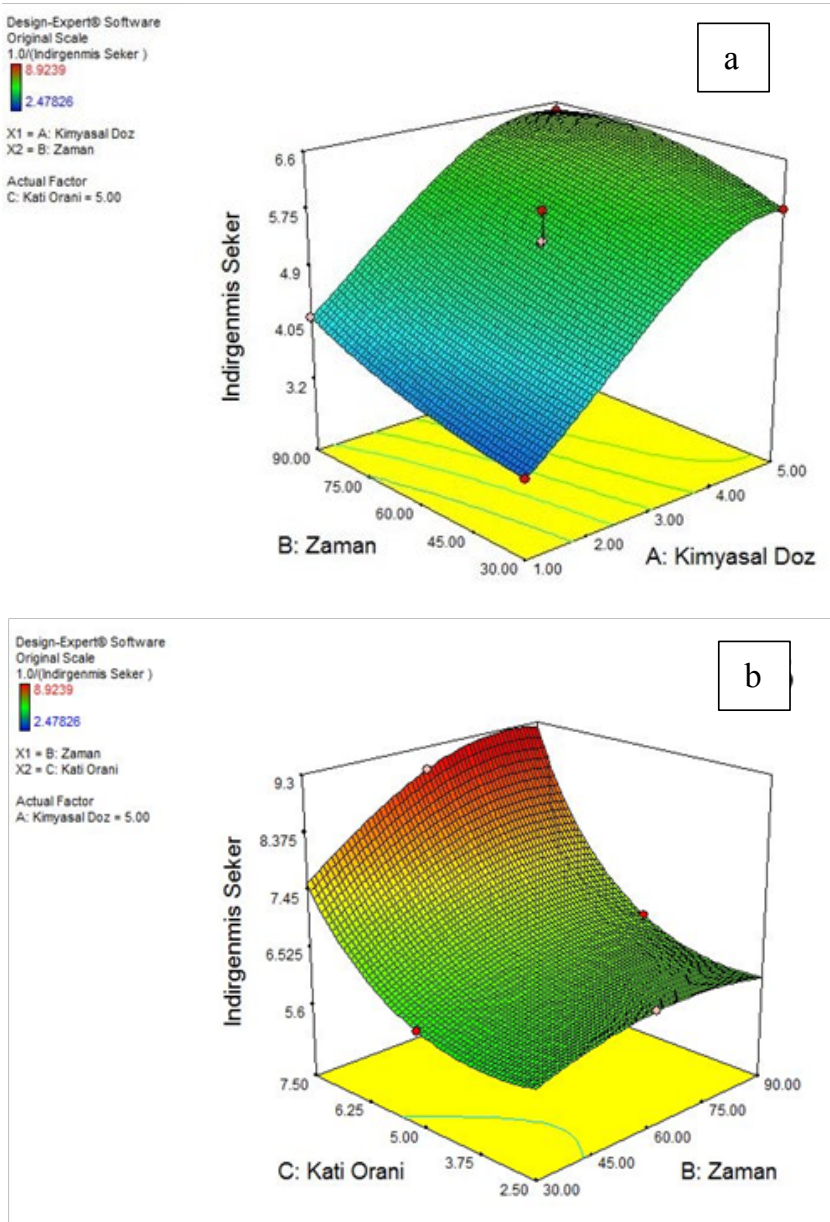


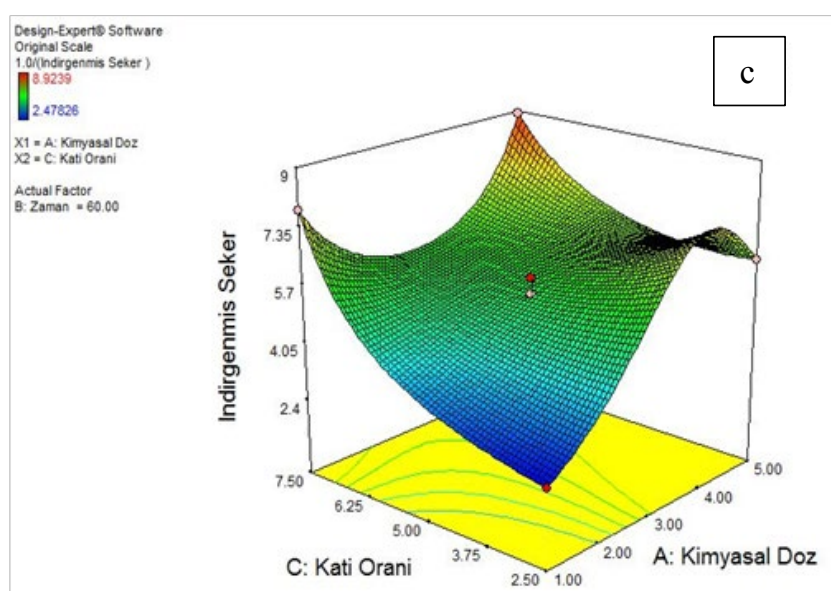

Şekil 4. Basınçsız KOH ön işlemi için farklı faktörlere bağlı indirgenmiş şeker konsantrasyonu

Mikrobiyal aktivite açısından oldukça kıymetli olan indirgenmiş şeker değeri Basınçsız koşullar için değerlendirilmesi Şekil 4'de ayrıntılı olarak verilmiştir. Toplam şeker değerine benzer şekilde zamana bağlı olarak $\mathrm{KOH}$ derişim etkisi incelendiğinde maksimum kimyasal doz (\%5) ve 90 dakikalık maksimum zamanda $8,92 \mathrm{~g} / \mathrm{L}$ maksimum indirgenmiş şeker değerine ulaşılmıştır. Zamana bağlı olarak katı oranı değerlendirildiğinde (Şekil 4b) zamanın maksimum değeri olan 90 dakika da maksimum katı oranında maksimum indirgenmiş şekere ulaşılmış ve bu değer toplam şeker reaksiyon tepkilerinde benzer faktörlerin benzer reaksiyon gösterdiği belirlenmiştir. Şekil $4 c$ Şekil $4 a$ ve $4 b$ ile birlikte incelendiğinde maksimum indirgenmiş şeker değerlerini elde etmek için belirlenen faktörlerin (zaman, katı oranı ve kimyasal doz) maksimum değerlerinde olduğu görülmektedir.

\section{SONUÇLAR}

Çalışmada, elma posalarının basınçlı ve basınçsız ortamlarda ön işlem koşullarının verimliliği yanıt yüzey metodolojisi ile araştırılmıştır. BoxBehnken deney dizaynından elde edilen yanıtlar incelendiğinde basınçlı ortamın reaksiyon süresini ve tepkisinde etkili olduğu görülmektedir. Basınçlı ortamda reaksiyon süresi 60 dakikada ve $\% 5$ oranında hammadde kullanımında toplam şeker miktarının 22,36 g/L'ye ulaştığı belirlenmiştir. Ayrıca basınçsız ortamda daha uzun reaksiyon süresi ve hammadde kullanımı maliyetli olması temiz teknoloji potansiyeli taşımadığını göstermektedir.

Yanıt yüzey metodolojisinde sıcaklık ve zaman faktörleri potasyum hidroksit prosesinde önemli değişkenlerdir. Çalışmaya göre potasyum hidroksit alkali ön işleminde en önemli etkinin sıcaklık ve basınç olduğu belirlenmiştir.

\section{KAYNAKLAR}

1. Aditiya, H.B., Mahlia, T.M.I., Chong, W.T., Nur, H., Sebayang, A.H., 2016. Second Generation Bioethanol Production: A Critical Review. Renew. Sustain. Energy Rev., Elsevier 66, 631-653.

2. Zhang, Y.H.P., 2008. Reviving the Carbohydrate Economy via Multi-product Lignocellulose Biorefineries. J. Ind. Microbiol. Biotechnol, 35, 367-375.

3. Takeuchi, K., Kauffman, J.M., Komiyama, H., Van Der Leeuw, S., Yoshikawa, H., Sri, T., Hamid, Z.A., 2018. Biofuels and Sustainability. Holistic Perspectives for Policymaking. Sci. Sustain. Soc.

4. Deveci, E.Ü., Gönen, Ç., 2018. Comparative Analysis of Strong and Weak Acid Pretreatment Methods Under Pressurized and Non-pressurized Conditions for Agro-industrial Waste of Apple Pulp. Energy Environ. 29, 1038-1052. 
5. Nicodème, T., Berchem, T., Jacquet, N. Richel, A., 2018. Thermochemical Conversion of Sugar Industry By-products to Biofuels. Renew. Sustain. Energy Rev., Elsevier 88, 151-159.

6. Voloshin, R.A., Rodionova, M.V., Zharmukhamedov, S.K., Nejat Veziroglu, T., Allakhverdiev, S.I., 2016. Review: Biofuel Production from Plant and Algal Biomass. Int. J. Hydrogen Energy, Elsevier 41, 17257-17273.

7. Mohr, A., Raman, S., 2015. Lessons from First Generation Biofuels and Implications for the Sustainability Appraisal of Second Generation Biofuels. Effic. Sustain. Biofuel Prod. Environ. Land-Use Res., Elsevier 63, 281-310.

8. Yaser, D., Kashif, S., Sarkar, B., Pallavi, R.B.M., $2019 . \quad$ 14-Biofuels: Their characteristics and Analysis. In In Woodhead Publishing Series in Composites Science and Engineering, Biomass, Biopolymer-Based Materials, and Bioenergy (Deepak Verma, Elena Fortunati, Siddharth Jain, X.Z., ed.), 277-325, Woodhead Publishing.

9. Basso, D., Patuzzi, F., Castello, D., Baratieri, M., Rada, E.C., Weiss-Hortala, E., Fiori, L., 2016. Agro-industrial Waste to Solid Biofuel Through Hydrothermal Carbonization. Waste Manag., Elsevier 47, 114-121.

10. Hassan, S.S., Williams, G.A., Jaiswal, A.K., 2018. Emerging Technologies for the Pretreatment of Lignocellulosic Biomass. Bioresour. Technol., Elsevier, 262, 310-318.

11. Jönsson, L.J., Martín, C., 2016. Pretreatment of Lignocellulose: Formation of Inhibitory byproducts and Strategies for Minimizing Their Effects. Bioresour. Technol. 199, 103-112.

12. Kumar, A.K., Sharma, S., 2017. Recent Updates on Different Methods of Pretreatment of Lignocellulosic Feedstocks: A Review. Bioresour Bioprocess. 4(1), 7. doi: 10.1186/s40643-017-0137-9.

13. Tomás-Pejó, E., Fermoso, J., Herrador, E., Hernando, H., Jiménez-Sánchez, S., Ballesteros, M., González-Fernández, C., Serrano, D.P., 2017. Valorization of Steamexploded Wheat Straw Through a Biorefinery Approach: Bioethanol and Bio-oil coproduction. Fuel 199, 403-412.
14. Dhillon, G.S., Kaur, S., Brar, S.K., 2013. Perspective of Apple Processing Wastes as Low-cost Substrates for Bioproduction of High Value Products: A Review. Renew. Sustain. Energy Rev., Elsevier 27, 789-805.

15. Sun, Y., Cheng, J., 2002. Hydrolysis of Lignocellulosic Materials for Ethanol Production: A Review. Bioresour. Technol., 83(1), 1-11.

16. Sendich, E., (Newton), Laser, M., Kim, S., Alizadeh, H., Laureano-Perez, L., Dale, B., Lynd, L., 2008. Recent Process Improvements for the Ammonia Fiber Expansion (AFEX) Process and Resulting Reductions in Minimum Ethanol Selling Price. Bioresour. Technol. 99, 8429-8435.

17. Persson, T., Ren, J.L., Joelsson, E., Jönsson, A.S., 2009. Fractionation of Wheat and Barley Straw to Access High-molecular-mass Hemicelluloses Prior to Ethanol Production. Bioresour. Technol., Elsevier 100, 3906-3913.

18. Júnior, A.D.N.F., Etchelet, M.I., Braga, A.F., M., Clavijo, L., Loaces, I., Noya, F., Etchebehere, C., 2020. Alkaline Pretreatment of Yerba Mate (Ilex Paraguariensis) Waste for Unlocking Low-cost Cellulosic Biofuel. Fuel, Elsevier, 266, 117068.

19. Bensah, E.C., Kádár, Z., Mensah, M.Y., 2019. Alkali and Glycerol Pretreatment of West African Biomass for Production of Sugars and Ethanol. Bioresour. Technol. Reports 6, 123-130.

20. Hu, Z., Wen, Z., 2008. Enhancing Enzymatic Digestibility of Switchgrass by Microwaveassisted Alkali Pretreatment. Biochem. Eng. J., 38, 369-378.

21. Xie, X., Feng, X., Chi, S., Zhang, Y., Yu, G., Liu, C., Li, Z., Li, B., Peng, H. 2018. A Sustainable and Effective Potassium Hydroxide Pretreatment of Wheat Straw for the Production of Fermentable Sugars. Bioresour. Technol. Reports, Elsevier, 3, 169-176.

22. Miller, G.L., 1959. Use of Dinitrosalicylic Acid Reagent for Determination of Reducing Sugar. Anal. Chem., 31, 426-428.

23. Dubois, M., Gilles, K.A., Hamilton, J.K., Rebers, P.A., Smith, F., 1956. Colorimetric Method for Determination of Sugars and Related Substances. Anal. Chem., 28, 350-356. 